\title{
Dairesel başlıklı savak akımının sayısal analizi
}

\author{
Numerical analysis of cylindrical weir flow
}

Nazire Göksu SOYDAN OKSAL*1,a

${ }^{1}$ Mersin Üniversitesi, Mühendislik Fakültesi, İnşaat Mühendisliği Bölümü, 33343, Mersin

\begin{tabular}{|c|c|c|}
\hline - Geliş tarihi / Received: 08.03.2021 & - Düzeltilerek geliş tarihi / Received in revised form: 17.05 .2021 & - Kabul tarihi / Accepted: 24.05 .2021 \\
\hline
\end{tabular}

\section{Öz}

Dairesel başlıklı savaklar akım ölçümleri için yaygın olarak kullanılan su yapılarıdır. Dikdörtgen kesitli savak profillerine göre genellikle daha yüksek debi katsayılarına sahip oldukları bilinen bu tür savaklar, akım yapısını daha az rahatsız etme özelliğine sahip oldukları için dikdörtgen başlıklı savaklara kıyasla daha avantajlıdır. Bu çalışmada, dairesel savakların etrafındaki akımın hız alanı, basınç dağılımı, akım çizgileri ve hız vektörleri sonlu hacim yöntemine dayalı ANSYS Fluent programı kullanılarak sayısal olarak incelenmiştir. Savak yapısından etkilenen akımı idare eden temel denklemler Renormalizasyon Grup $k-\varepsilon$ (RNG) modeli ile çözülmüştür. Akımın su yüzünün hesabında Akışkan Hacimleri Yöntemi (Volume of Fluid-VOF) kullanılmıştır. RNG modelinden elde edilen sayısal sonuçlar, literatürden elde edilen deneysel ölçümler ile doğrulanmıştır. Bununla birlikte deneysel sonuçlara ek olarak farklı akım koşulları için sayısal modellemeler gerçekleştirilmiş ve sayısal debi katsayıları $\left(C_{\mathrm{d}}\right)$ elde edilmiştir. Deneysel ve sayısal hız dağılımları ile debi katsayılarının karşılaştırılmasından, RNG modelinin dairesel savak etrafındaki akım alanını tahmin etmede başarılı olduğu sonucuna varılmıştır. Ayrıca debinin artırılmasının dairesel savaklar için debi katsayısında artışa neden olduğu belirlenmiştir.

Anahtar kelimeler: Dairesel başlıklı savaklar, Debi katsayısı, Hız profilleri, Sayısal modelleme

\begin{abstract}
Circular-crested weirs are flow structures commonly used for flow measurements. These types of weirs, which are generally known to have higher discharge coefficients compared to rectangular weir profiles, are widely used because they have less disturbance to the flow structure. In this study, the velocity field, pressure distribution, streamlines and velocity vectors of the flow around circular crested weirs were numerically investigated using the ANSYS Fluent program based on the finite volume method. The governing equations of the flow affected by the weir structure are solved by the Renormalization Group k- $\varepsilon(R N G)$ model. The Volume of Fluid-VOF was used to calculate the free surface of the flow. The numerical results obtained from the RNG model have been verified by experimental measurements obtained from the literature. However, in addition to the experimental results, numerical modeling was performed for different flow conditions and numerical velocity distributions, free surface profiles, streamlines and velocity vectors and discharge coefficients $C d$ were obtained. The comparison of the experimental and numerical velocity distributions and the discharge coefficients showed that the RNG model was successful in estimating the flow around the circular weir. It can also be said that increasing the flow rate causes an increase in the discharge coefficient for circular weir.
\end{abstract}

Keywords: Circular crested weirs, Discharge coefficient, Velocity profile, Numerical modelling

\footnotetext{
*a Nazire Göksu SOYDAN OKSAL; goksusoydan@mersin.edu.tr; Tel: (0324) 36100 01; orcid.org/0000-0001-6469-2649
} 


\section{Giriş}

Savaklar, debi ölçümleri, su seviyelerinin düzenlenmesi ve suların yönlendirilmesi için kullanılan en eski hidrolik yapılardır. Savaklar üzerinden geçen akımın yapısı incelendiğinde dairesel başlıklı savaklar, dar tepeli savaklar (Rao, 1975) veya k1sa tepeli savaklar (Bos, 1976) olarak sınıflandırılır. Bu tür savak yapıları için önemli olan savak yapısının etkisinde olan bölgede akım çizgilerinin eğriliğidir. Dairesel başlıklı savaklar genellikle akım çizgilerinin eğriliğinin daha fazla olması açısından geniş başlıklı savaklardan farklı1ık gösterirler. Dairesel başlıklı savakların, keskin kenarlı ve geniş başlıklı savaklarla kıyaslandığında daha yüksek debi katsayılarına sahip oldukları görülmektedir (Dönmez ve Lekesiz, 2011; Schmocker vd., 2011; Bagheri ve Kabiri-Samani, 2020). Debi katsayıs $C_{d}$, Bos (1976) tarafindan Denklem (1)'deki gibi ifade edilmiştir. Burada $q$, birim boy debisini, $H$ toplam enerji yüksekliğini ve $C_{\mathrm{d}}$ debi katsayısını ifade etmektedir.

$$
q=C_{d} \frac{2}{3} \sqrt{\frac{2}{3}} g H^{3 / 2}
$$

Savak etrafındaki akımın özelliklerini belirlemek için geçmişte birçok deneysel ve sayısal çalışmalar yapılmıştır (Şimşek vd., 2016; Gümüş ve Şimşek, 2015; Aköz vd., 2019; Soydan vd., 2012). Bu çalışmalarda, savaklar için elde edilen debi katsayılarının yanında, savak etrafındaki akımın özellikleri üzerinde de durulduğu görülmüştür. Ancak, literatür incelendiğinde dairesel başlıklı savakların debi katsayılarının sayısal olarak doğrulanması ve elde edilmesi konusunda çok fazla çalışmanın bulunmadığı görülmüştür. Heidarpour ve Chamani (2006), silindir savak kreti üzerinden geçen akımın çevrintisiz olduğu kabulü ile hız dağ 11 ımını tahmin etmek için potansiyel akım teorisine dayanan bir metot geliştirmişlerdir. Yaptıkları çalışmada farklı yarıçap ve yüksekliklere sahip silindirik savaklar etrafindaki akımın hız dağılımı Prandlt tüpü ile ölçülmüştür. Önerdikleri yöntemin hız dağılımını belirlemede başarılı olduğu belirlenmiş ve debi katsayısının yaklaşan akımın toplam enerji yüksekliği $(H)$ ve kret yarıçapı (R) ile ilişkili olduğu sonucuna varılmıştır. Chanson ve Montes (1998), çalışmalarında sekiz farklı çapta ve farklı yüksekliklerdeki silindir savaklar üzerinden geçen akımı beş farklı debi koşulu için deneysel olarak incelemişlerdir. Yapılan deneysel araştırmalar neticesinde silindir boyutunun, savak yüksekliğinin ve savağın memba eğiminin, debi katsayısı, kretteki su yüksekliği ve enerji dağılımı üzerinde etkisi olmadığ 1 sonucuna varmışlardır. Bunun yanında akım koşullarının debi katsayısını ve kretteki akım özelliklerini etkilediğini belirtmişlerdir. Aköz vd., (2014), dairesel savak üzerinden geçen akımın hız alanını Lazer Doppler anemometresi ile deneysel olarak elde etmişlerdir. Deneylerle benzer duruma sahip akım durumunun sayisal modellemesinde, Standart $k-\varepsilon$, Renormaliation $k-\varepsilon$, Realizable $k-\varepsilon$, Modifiye $k-w$, Shear Stress Transport ve Reynolds Stress türbülans modellerini kullanmışlardır. Sayısal bulguların deneysel ölçümlerle karşılaştırılmasından, Reynolds Stress modelin akımın hı alanını ve su yüzü profillerini belirlemede kullanılan diğer modellere kıyasla daha başarılı olduğu sonucuna varmışlardır. Yüce vd., (2015), silindirik savakların kanal içerisindeki eğikliğinin; akımın hız dağılımı, basınç dağılımı ve su derinliğinin savak tepesi üzerindeki dağılımı üzerindeki etkilerini araştırmak için hesaplamalı akışkanlar dinamiği yöntemini kullanmışlardır. Farklı akım ve yapı koşullarında SSG Reynolds Gerilmeleri Modelini kullanarak elde ettikleri sayısal sonuçlardan akım çizgilerinin akım yönüne göre eğimden etkilendiği sonucuna varmışlardır. Ayrıca savak eğim açısının artışının, savağın mansap yüzünde akım hızının artmasına sebep olduğu ve buna bağlı olarak yine bu bölgede negatif basıncın mutlak değerini arttırdığı görülmüştür. Literatürde yapılan incelemeler sonucunda dairesel savaklar ile ilgili çalışmaların genelinde debi katsayılarının deneysel olarak elde edildiği; sayısal modellemelerle elde edilen debi katsayılarının deneysel sonuçlarla doğrulanmasına dayalı çalışmaların yetersiz olduğu görülmüştür. Sayısal model çalışmalarının arttırılmasının farklı akım-yap1 etkileşimleri konusunda fayda sağlayacağı düşünülmektedir.

$\mathrm{Bu}$ çalışmada dairesel savak etrafindan geçen akım farklı debi koşulları için sayısal olarak modellenmiş ve deneysel veriler kullanılarak doğrulanmıştır. Akım özelliklerinin belirlenmesinde, hareket denklemleri ANSYS Fluent programı yardımıyla sayısal olarak çözülmüştür. Su yüzünün sayısal olarak belirlenmesinde ise Akışkan Hacimler Yöntemi (VOF) kullanılmıştır. Akımın hız alanının ve su yüzünün belirlenmesinde Renormalization $k-\varepsilon$ (RNG) türbülans modeli kullanılmış ve farklı debi durumlarındaki hız profilleri, su yüzü profilleri, akım çizgileri ve hız vektörleri değerlendirilmiştir. Ayrıca elde edilen sayısal debi katsayıları $C_{\mathrm{d}}$, deneysel verilerle karşılaştırılmış ve RNG modelinin dairesel savak akımlarını modellemede başarısı araştırılmıştır. 


\section{Materyal ve yöntem}

\subsection{Deneyler}

Deneyler $7 \mathrm{~m}$ uzunluğunda $0.32 \mathrm{~m}$ derinliğinde ve $0.35 \mathrm{~m}$ yüksekliğindeki yan duvarları pleksiglass'tan yapılmış dikdörtgen kesitli açık kanal modelinde gerçekleştirilmiştir (Heidarpour ve Chamani, 2006). Yarıçapı $\mathrm{R}=6.3 \mathrm{~cm}$ olan dairesel savak yapısı, kanal giriş kesitinin $\mathrm{x}=5.0 \mathrm{~m}$ mansabına yerleştirilmiştir (Şekil 1). Kanalın memba bölgesinde ölçülen hız profillerinin gelişmiş akım bölgesinde olmasına dikkat edilmiştir. Hacimsel debi $\pm \% 3$ hassasiyetle, akımın hız alanı ise $2 \mathrm{~mm}$ çapa sahip Prandtl tüpü ile ölçülmüştür. Hız ölçümlerinin doğruluğunun belirlenmesi için hiz profillerinin integrasyonu ile elde edilen debi değerleri, ölçüm değerleri ile karşılaştırılmış ve hata payı $\pm \% 5$ olarak elde edilmiştir. Tablo 1'de, bu çalışmada kullanılan sayısal ve deneysel akım özellikleri verilmiştir. Burada $q$, birim genişlik debisini; $H$, akımın dairesel savak yüzünden 2D membasındaki $(D=$ dairesel savak çapı) yaklaşım akımının kret yüksekliğinden itibaren enerji yüksekliğini $(x=4,75 \mathrm{~m})$; Fr, akımın dairesel savak yüzünden 2D membasındaki Froude sayısını ve $\mathrm{Re}_{\mathrm{D}}$ ise dairesel savağın çapına bağlı Reynolds sayısını ifade etmektedir. Bu çalışmada Heidarpour ve Chamani (2006)'nın dairesel savaklar için yapmış olduğu deneysel çalışmaların ( $\left.1_{\text {deney }}, 2_{\text {deney }}, 3_{\text {deney }}, 4_{\text {deney }}\right)$ sayısal olarak modellenmesi ve sonuçların deneysel verilerle karşılaş̧ırılmasına ek olarak bunlardan farklı 4 akım koşulu için sayısal modellemeler gerçekleştirilmiştir $\left(5_{\text {sayısal }}, 6_{\text {sayssal }}\right.$, 7 sayisal, $8_{\text {sayisal }}$. Elde edilen sayısal hiz profilleri ve $C_{\mathrm{d}}$ debi katsayıları, deneysel bulgularla karşılaştırılmış ve doğrulanmıştır. Bunun yanından sayısal verilerden elde edilen 8 farklı akım koşulu için akım çizgileri, hız vektörleri ve basınç dağılımları değerlendirilmiştir.

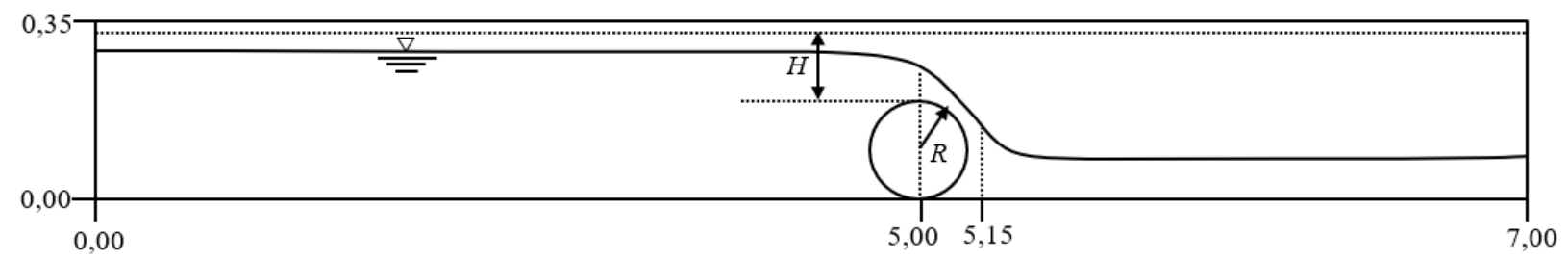

Şekil 1. Dairesel savak akımının deneysel gösterimi

Tablo 1. Sayısal ve deneysel akım özellikleri

\begin{tabular}{lccccc}
\hline & $\mathbf{q}(\mathbf{l} / \mathbf{s} / \mathbf{m})$ & $\mathbf{R}(\mathbf{c m})$ & $\mathbf{H}(\mathbf{c m})$ & $\mathbf{F r}$ & $\mathbf{R e}_{\mathbf{D}}$ \\
\hline $\mathbf{1}_{\text {(deney) }}$ & 16.60 & 6.3 & 4.11 & 0.0779 & 10,749 \\
$\mathbf{2}_{\text {(deney) }}$ & 17.50 & 6.3 & 4.32 & 0.0806 & 11,197 \\
$\mathbf{3}_{\text {(deney) }}$ & 23.40 & 6.3 & 5.07 & 0.1013 & 14,359 \\
$\mathbf{4}_{\text {(deney) }}$ & 31.20 & 6.3 & 6.06 & 0.1263 & 18,363 \\
$\mathbf{5}_{\text {(sayisal) }}$ & 51.80 & 6.3 & 8.20 & 0.1785 & 27,299 \\
$\mathbf{6}_{\text {(sayisal) }}$ & 54.60 & 6.3 & 8.52 & 0.1842 & 28,370 \\
$\mathbf{7}_{\text {(sayisal) }}$ & 73.15 & 6.3 & 10.05 & 0.2249 & 35,724 \\
$\mathbf{8}_{\text {(sayisal) }}$ & 97.65 & 6.3 & 12.03 & 0.2690 & 44,322 \\
\hline
\end{tabular}

\subsection{Temel denklemler}

Dairesel savak üzerinden geçen akım düzenli, ikiboyutlu, sıkışmayan, türbülanslı ve serbest yüzeyli bir akımdır. Akım hareketi ve özelliklerinin belirlenmesinde kullanılan temel denklemler, kütlenin korunumu ve momentumun korunumu (Reynolds-ortalamalı Navier-Stokes denklemleri), denklemleridir ve aşağıda verilmiştir.

$$
\frac{\partial \bar{u}_{i}}{\partial x_{i}}=0
$$

$$
\rho\left(\frac{\partial \bar{u}_{i}}{\partial t}+\bar{u}_{j} \frac{\partial \bar{u}_{i}}{\partial x_{j}}\right)=\rho g_{i}-\frac{\partial \bar{p}}{\partial x_{i}}+\mu \frac{\partial^{2} \bar{u}_{i}}{\partial x_{j}^{2}}+\frac{\partial \tau_{i j}}{\partial x_{j}}
$$

Denklem (2) ve (3)'te, $u_{\mathrm{i}}, x_{\mathrm{i}}$ doğrultusundaki ortalama hız bileşeni, gi yer çekimi ivmesi, $p$ ortalama basınç, $\mu$ dinamik viskozite, $\rho$ suyun yoğunluğu ve $\tau_{\mathrm{ij}}$ türbülans (Reynolds) gerilmeleridir.

Genel halde, üç-boyutlu akım alanında, Denklem (2) ve (3) ile verilen 4 denklem 10 adet bilinmeyen içermektedir, bunlar: üç hız bileşeni $\bar{u}_{i}$, basınç $\bar{p}$, ve altı bağımsız Reynolds gerilmesi $-\rho \overline{u_{i}^{\prime} u_{j}^{\prime}}$, dir. 
Buna göre, 10 adet bilinmeyenin çözümü için 4 denklemin mevcut olması bilinmeyen açısından denklem sisteminin kapatılamayacağı anlamına gelmektedir. Denklem sisteminin çözümü için türbülans gerilmelerinin tanımlanmasına ihtiyaç duyulmaktadır. $\mathrm{Bu}$ sorun denklemlerde yer alan türbülans gerilmelerinin türbülans kapatma modelleri ile tanımlanmasi yardımıyla çözülebilmektedir. Bu çalışmaya konu olan akım için Denklem (2) ve (3) iki-boyutlu olarak çözülmüştür. Türbülans viskozitesinin doğrusal formda formülasyonunu esas alan Boussinesq yaklaşımına göre Denklem (3)'teki türbülans gerilmeleri, sıkışmayan akımlar için, Denklem (4)'te verilmiştir.

$$
\tau_{i j}=-\rho \overline{u_{i}^{\prime} u_{j}^{\prime}}=\mu_{t}\left(\frac{\partial \bar{u}_{i}}{\partial x_{j}}+\frac{\partial \bar{u}_{j}}{\partial x_{i}}\right)-\frac{2}{3} \rho k \delta_{i j}
$$

Burada $u_{i}^{\prime}$ ve $u_{j}^{\prime}$ yatay ve düşey türbülans hız sapınçları, $\mu_{t}$ türbülans viskozitesi, $k\left(=\overline{u_{i}^{\prime} u_{i}^{\prime}} / 2\right)$ türbülans kinetik enerjisi ve $\delta_{i j}$ Kronecker delta'dır.

\subsection{Türbülans modeli}

Akımın bir yapı ile etkileşim halinde olduğu açık kanallarda, akımın hareket denklemlerinin çözümleri, Hesaplamalı Akışkanlar Dinamiği (HAD) yöntemleri ile gerçekleştirilebilmektedir. Akımın modellenmesinde, Denklem (4)'teki $\mu_{\mathrm{t}}$ türbülans viskozitesinin hesaplanmasında birçok türbülans modeli geliştirilmiştir (Wilcox, 2006; Menter, 1994; Yakhot ve Orszag, 1986; Yakhot ve Smith, 1992). Bu çalışmada dairesel savak etrafındaki akımın sayısal olarak modellenmesi ve hız alanının, su yüzü profillerinin ve bu değerlere bağlı olarak debi katsayısının belirlenmesi için Renormalization $k-\varepsilon$ (RNG) türbülans modeli kullanılmıştır. RNG türbülans modelinin akımda meydana gelen ayrılmaların ve eğriselliğin bulunması durumunda başarılı sonuçlar verdiği modeli geliştirenler tarafından iddia edilmiştir.

\subsubsection{Renormalization group $k-\varepsilon(R N G)$ modeli}

RNG $k-\varepsilon$ türbülans modeli iki denklemli bir modeldir. Yakhot ve Orszag (1986)'nın geliştirilmiş olup (Yakhot ve Smith, 1992) esasen Navier-Stokes denklemlerinden renormalization group teorisi kullanılarak elde edilmiştir. RNG k-E türbülans modeli ile; türbülans viskozitesi $\mu_{i}$; Denklem (5)'te verildiği gibi türbülans kinetik enerjisi, $k$, ve türbülans kinetik enerjisi kayıp oranı, $\varepsilon$ 'na bağlı olan denklemin çözülmesi ile elde edilmektedir.

$$
\mu_{t}=\rho C_{\mu} \frac{k^{2}}{\varepsilon}
$$

$C_{\mu}$ boyutsuz bir model sabitini ifade etmektedir. Denklem (5)'teki $k$ ve $\varepsilon$ değerlerinin hesaplanabilmesi, Denklem (6) ve Denklem (7)'de verilen iki tane kısmi diferansiyel taşınım denkleminin sayısal olarak çözülmesi işlemine bağl1 olarak gerçekleşmektedir.

$$
\begin{aligned}
& \frac{\partial(\rho k)}{\partial t}+\bar{u}_{j} \frac{\partial(\rho k)}{\partial x_{j}}=\frac{\partial}{\partial x_{j}}\left[\left(\mu+\frac{\mu_{t}}{\sigma_{k}}\right) \frac{\partial k}{\partial x_{j}}\right]+\tau_{i j} \frac{\partial \bar{u}_{i}}{\partial x_{j}}-\rho \varepsilon \\
& \frac{\partial(\rho \varepsilon)}{\partial t}+\bar{u}_{j} \frac{\partial(\rho \varepsilon)}{\partial x_{j}}=\frac{\partial}{\partial x_{j}}\left[\left(\mu+\frac{\mu_{t}}{\sigma_{\varepsilon}}\right) \frac{\partial \varepsilon}{\partial x_{j}}\right]+C_{1 \varepsilon}^{*} \frac{\varepsilon}{k} \tau_{i j} \frac{\partial \bar{u}_{i}}{\partial x_{j}}-C_{2 \varepsilon} \rho \frac{\varepsilon^{2}}{k}
\end{aligned}
$$

Model sabitleri aşağıdaki gibi verilmiştir:

$$
\begin{array}{lcc}
C_{\mu}=0.0845 & C_{\mu}=0.0845 \quad C_{1 \varepsilon}^{*}=C_{1 \varepsilon}-\frac{\eta\left(1-\eta / \eta_{0}\right)}{1+\beta \eta^{3}} & C_{2 \varepsilon}=1.68 \quad C_{1 \varepsilon}=1.42 \\
\eta=\left(2 S_{i j} S_{i j}\right)^{1 / 2} \frac{k}{\varepsilon} \quad S_{i j}=\frac{1}{2}\left(\bar{u}_{i, j}+\bar{u}_{j, i}\right) & \eta_{0}=4.377 & \beta=0.012 \text { (deneysel) }
\end{array}
$$

\section{$S_{i j}$ şekil değiştirme hızı parametresidir. Denklem}

(7)'de, akışkan şekil değiştirmesine bağlı $\eta$ parametresinin olduğu görülmektedir. $\mathrm{Bu}$ şekil değiştirme parametre sayesinde RNG $k$ - $\varepsilon$ türbülans modelinin eğri yörüngeli akımlarda SKE modeline göre daha gerçekçi sonuçlar verdiği iddia edilmiştir (Yakhot ve Smith, 1992). 


\subsection{Serbest yüzeyin hesaplanmasında akışkan hacimleri (VOF) yöntemi}

Akımın bir yapı ile etkileşimde bulunduğu açık kanal akımlarının sayısal modellemelerinde, akım profilinin hesaplanmasında Akışkan Hacimleri yöntemi (Volume of Fluid- VOF) yaygın bir şekilde kullanılmaktadır (Hirt ve Nichols, 1981; Aköz vd., 2014; Gümüş ve Şimşek, 2015). Bu yöntem, sayısal hesaplamada kullanılan ağ yapısında, sıvı ile havanın temas ettiği sınır bölgesindeki ağ elemanlarının hacimlerinin akışkan ile ne kadar dolu olduğunun oransal olarak hesaplanmasını esas almaktadır. Akışkanın doluluk oranı olarak ifade edilen $F$ değeri ağ elemanı sıv1 ile tamamen dolu ise " 1 ", boş ise "0" ve kısmen dolu ise " $0<F<1$ " değerlerini almaktadır (Şekil 2). Böylelikle farklı zaman adımlarında hesaplama ağı içerisinden geçen akımın yüzeyinin ağ içerisindeki konumu belirlenmiş olur. VOF yöntemi ile serbest yüzeyin hesaplanmasında üç aşama bulunmaktadır. Öncelikle serbest yüzeyin yeri bulunur; daha sonra bu yüzey, su ve hava arasında keskin bir arakesit olarak belirlenir. Son olarak bu arakesite sinır şartları uygulanır. Arakesit üzerinde sıfır kayma gerilmesi ve sabit basınç sınır koşulları uygulanmaktadır. Akışkan Hacimleri yöntemi ile akım profilinin belirlenmesinde "GeoReconstruct" yaklaşımı kullanılmıştır (ANSYS, 2012). Bu yaklaşımda ilk olarak ağ elemanının doluluk oranı kullanılarak hava-su doğrusal ara yüzünün ağ elemanının ağırlık merkezine göre yeri belirlenir. Daha sonra hesaplanmış ara yüzün yeri ve eleman yüzeylerindeki normal ve teğetsel hız bilgileri kullanılarak ağ elemanı yüzeyinden taşınan akışkan miktarları hesaplanır. En sonunda taşınan akışkan miktarları göz önüne alınarak, kütlenin korunumu denklemi ile her hücrenin doluluk oranı hesaplanır (Soydan, 2019).

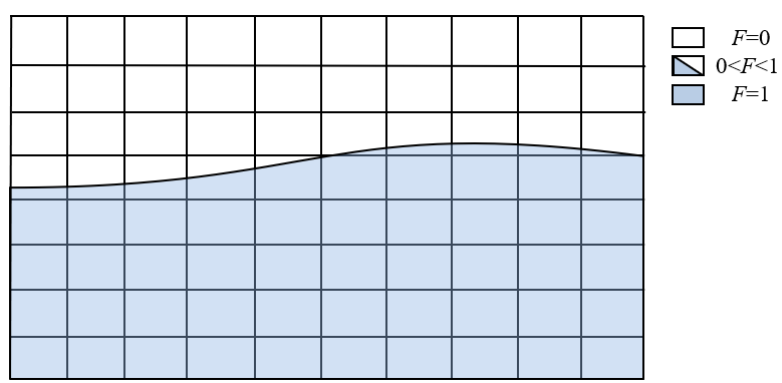

Şekil 2. A $\breve{g}$ elemanın dolu, boş ve kısmen dolu olduğu durumlar

\section{5. Çözüm bölgesi, sınır ve başlangıç şartları}

Şekil 3’te, dairesel savak etrafindaki türbülanslı açık kanal akımının sayısal modelinde kullanılan çözüm bölgesi ve sınır şartları verilmiştir. Kanal kesitinin sol alt köşesi, kanalın başlangıç noktası olarak belirlenmiştir. Şekil 3'te görüldüğg̈ üzere çözüm bölgesi, akım-yap1 etkileşiminin olduğu bölgelere ve katı sınırlara doğru ağ sıklaştırması yapmak amacıyla 10 alt bölgeye ayrılmıştır. Çözüm bölgesinin üst sınırı ve çıkış bölgesi sınır şartı $p=0$, kanal tabanı ve dairesel savak yüzeyi sıfır-hız sınır şartı, $u=0, v=0$ olarak tanımlanmıştır. Giriş sınır şartı olarak dairesel savak akımları için 8 farklı akım koşulu için sırasıyla, $u=0,047,0,050$, $0,067,0,089,0,148,0,156,0,209,0,279 \mathrm{~m} / \mathrm{s}$ değerleri alınmıştır. Düşey hız bileşeni için $v=0$ sınır şartı kullanılmıştır. Serbest su yüzeyinin belirlenmesi için kullanılan akışkan hacimleri (VOF) yönteminde, sayısal analizlerin başlangıcında tüm akım bölgesi boş olarak kabul edilmiş, giriş sınırında $F=1$, çıkış kesiti ve diğer bölgeler için $F=0$ başlangıç şartı alınmıştır. Şekil 4 'te bu çalışmada sayısal analizlerde kullanılan ăg yapıs1 görülmektedir. Şekilden de görüldüğü gibi katı sınırlara doğru sıklaştırmalar yapılmış ve sayısal analizlerde duvar fonksiyonu olarak Enhanced Wall Treatment kullanılmıştır (ANSYS, 2012). Bu fonksiyon, katı sınıra en yakın ağ yüksekliğinin viskoz alt tabaka içerisinde olduğu kabulüne dayanarak çözüm yapmaktadır. Kırkgöz ve Ardıçlıoğlu (1997), $y^{+}\left(=u^{*} y / v\right)$ değerinin $10^{\prime}$ dan küçük olduğu durumlar için, viskoz alt tabakadaki hız dağılımının lineer dağılıma uyduğunu rapor etmişlerdir ( $u^{*}$ : kayma hızı; $y$ : yükseklik; v:suyun kinematik viskozitesi). Bu kriter göz önünde bulundurularak, çözüm bölgesinde katı sınırlara doğru yapılan sıklaştırmalar neticesinde duvara yakın elemanların, $y^{+} \leq 10$ olacak şekilde boyutsuz cidar mesafesi değerlerine sahip olmalarına dikkat edilmiştir. Şekil 5'te kanal boyunca sayısal modellemeden elde edilen $y^{+}$değerleri incelendiğinde tüm bölgelerde $y^{+}$değerinin 10'un altında kaldığ 1 görülmekte ve sıklaştırmanın yeterli olduğu sonucu anlaşılmaktadır. Tablo 2'de 10 farklı alt bölge için kullanılan eleman sayıları verilmiştir. 


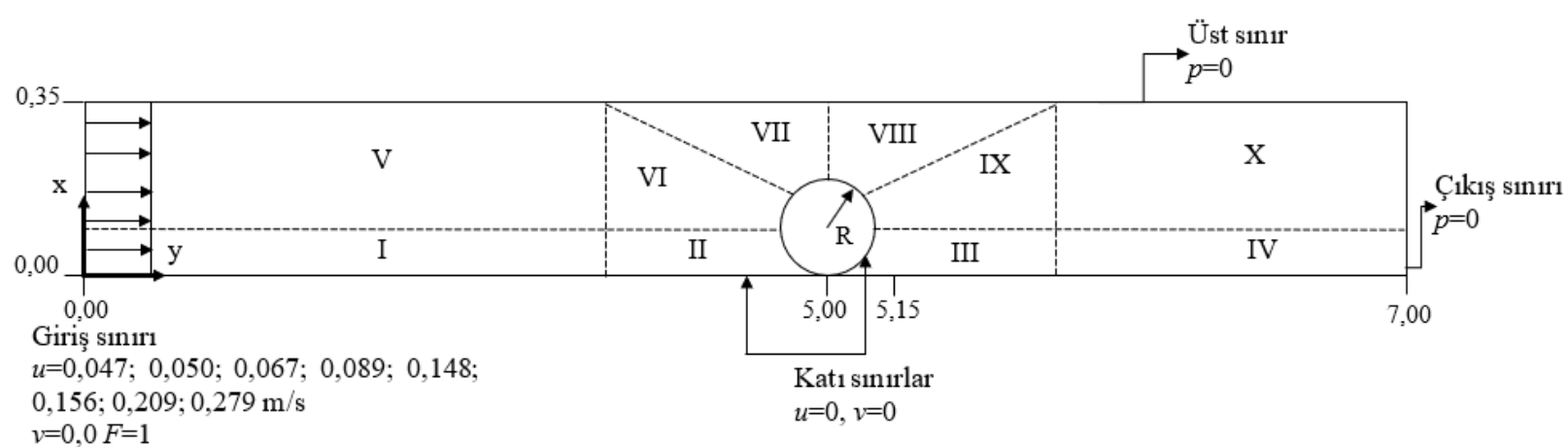

Şekil 3. Sayısal modellemede kullanılan çözüm bölgesi ve sınır şartları

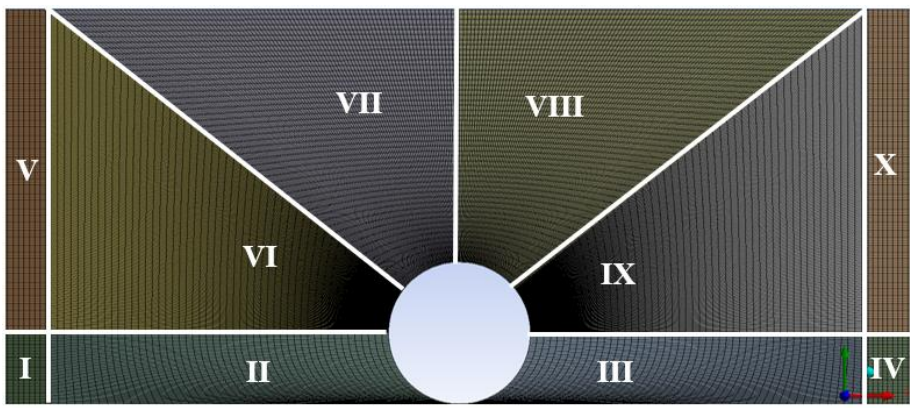

Şekil 4. Sayısal hesaplama ağı ve alt bölgeleri

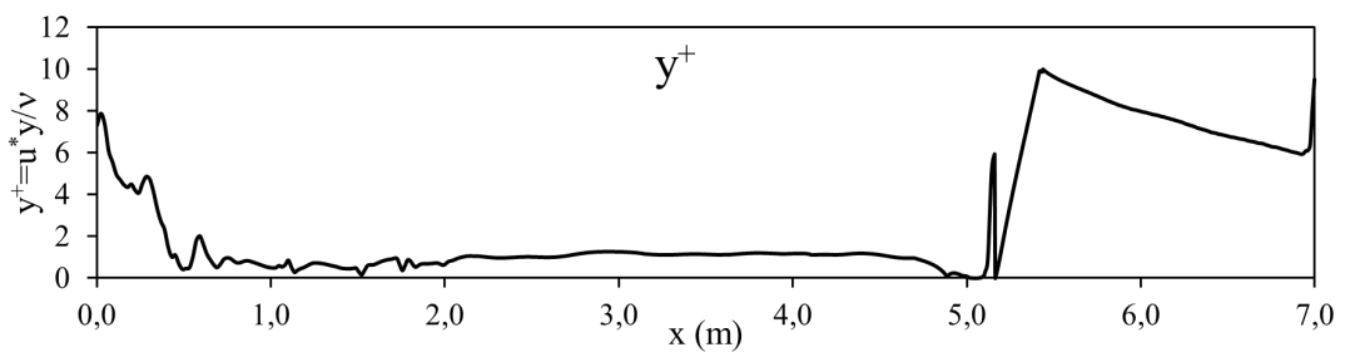

Şekil 5. RNG türbülans modeli ile hesaplanan $y^{+}$değerinin kanal tabanı boyunca değişimi

Tablo. 2. Hesaplama ağındaki eleman sayıları

\begin{tabular}{cccc}
\hline Bölge & $\begin{array}{c}\text { Eleman } \\
\text { SayısI }\end{array}$ & Bölge & $\begin{array}{c}\text { Eleman } \\
\text { SayısI }\end{array}$ \\
\hline I & $500 X 150$ & VI & $100 X 250$ \\
\hline II & $100 X 150$ & VII & $100 X 50$ \\
\hline III & $100 X 150$ & VIII & $100 \times 50$ \\
\hline IV & $250 X 150$ & IX & $100 \times 250$ \\
\hline V & $500 X 250$ & X & $250 \times 250$ \\
\hline
\end{tabular}

\section{Bulgular ve tartışmalar}

\subsection{Deneysel ve sayısal hiz profilleri}

Bu çalışmada Heidarpour ve Chamani (2006)'nın silindir savak üzerinden geçen akımın 4 farklı debi durumu için elde ettiği deneysel sonuçlar sayısal olarak modellenerek, elde edilen sonuçlar deneysel verilerle karşılaştırılmıştır. Bununla birlikte 8 farklı debi durumu için elde edilen debi katsayıları sayısal sonuçların doğrulanması için kullanılmıştır.
Şekil 6' da 4 farklı debi durumu için kret noktasında elde edilen deneysel hız profilleri RNG modeli ile elde edilen sayısal hiz profilleri ile karşılaş̧ırılmışıtır. Şekillerde y eksenindeki su yüksekliği dairesel savağın kret yarıçapı $\mathrm{R}$ ile, $\mathrm{x}$ ekseninde verilen $u$ hızları ise her debi için elde edilen giriş bölgesindeki kesit ortalama hızı $\mathrm{U}_{1}$ ile boyutsuzlaştırılmıştır. RNK $k-\varepsilon$ türbülans modeli ile elde edilen sayısal boyutsuz hiz profillerinin deneylerle gayet uyumlu olduğu anlaşılmaktadır. Bununla birlikte sayısal hiz profilleri ile deneysel hız profillerinin katı sinıra yakın yani; hız gradyanının maksimum olduğu bölgede oldukça uyumlu olduğu buna bağlı olarak elde edilen ağ yapısının katı sınır bölgesinde yeterince sikı olduğu anlaşılmaktadır. Elde edilen karşılaştırmalardan eğri yörüngeli akımları modellemede başarılı olduğu bilinen RNG türbülans modelinin silindir savak akımını modellemede oldukça başarılı olduğu sonucuna varılmıştır. Şekil 7'de, 8 farklı akım durumu için sayısal modellemeden elde 
edilen a) x doğrultusundaki yatay hız bileşeni, $(u)$; b) y doğrultusundaki düşey hız bileşeni, (v) dağ 1 lımı verilmektedir. Şekiller incelendiğinde kret noktasından sonra akım eğriselliğinin debinin artmas1 ile azaldığ 1 görülmektedir. Buna bağl1 olarak kretin hemen mansabında y doğrultusundaki hız bileşeninin hakimiyetinin debinin az olduğu bölgelerde daha fazla olduğu görülmektedir. X
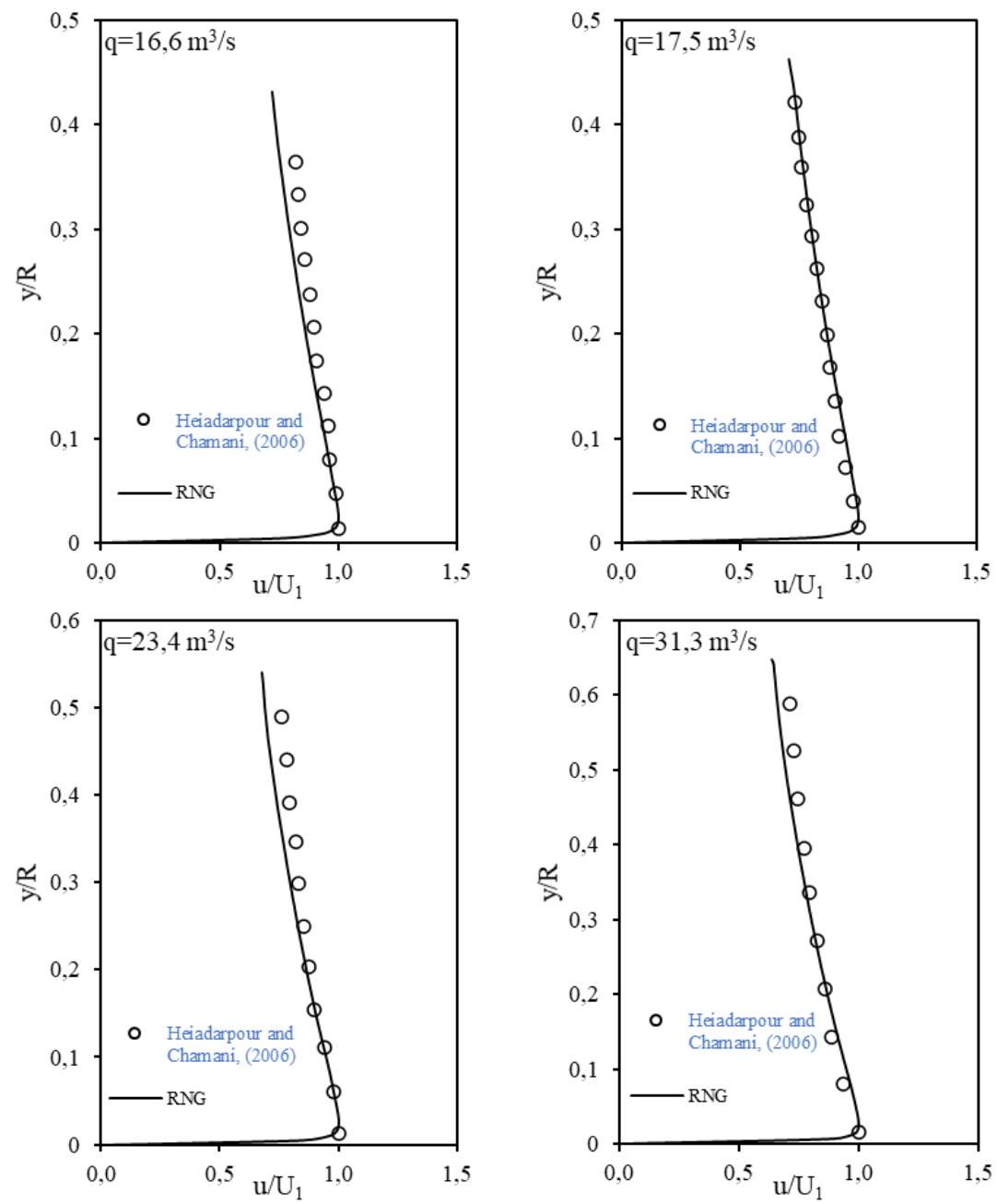

Şekil 6. Deneysel ve sayısal hız profilleri 

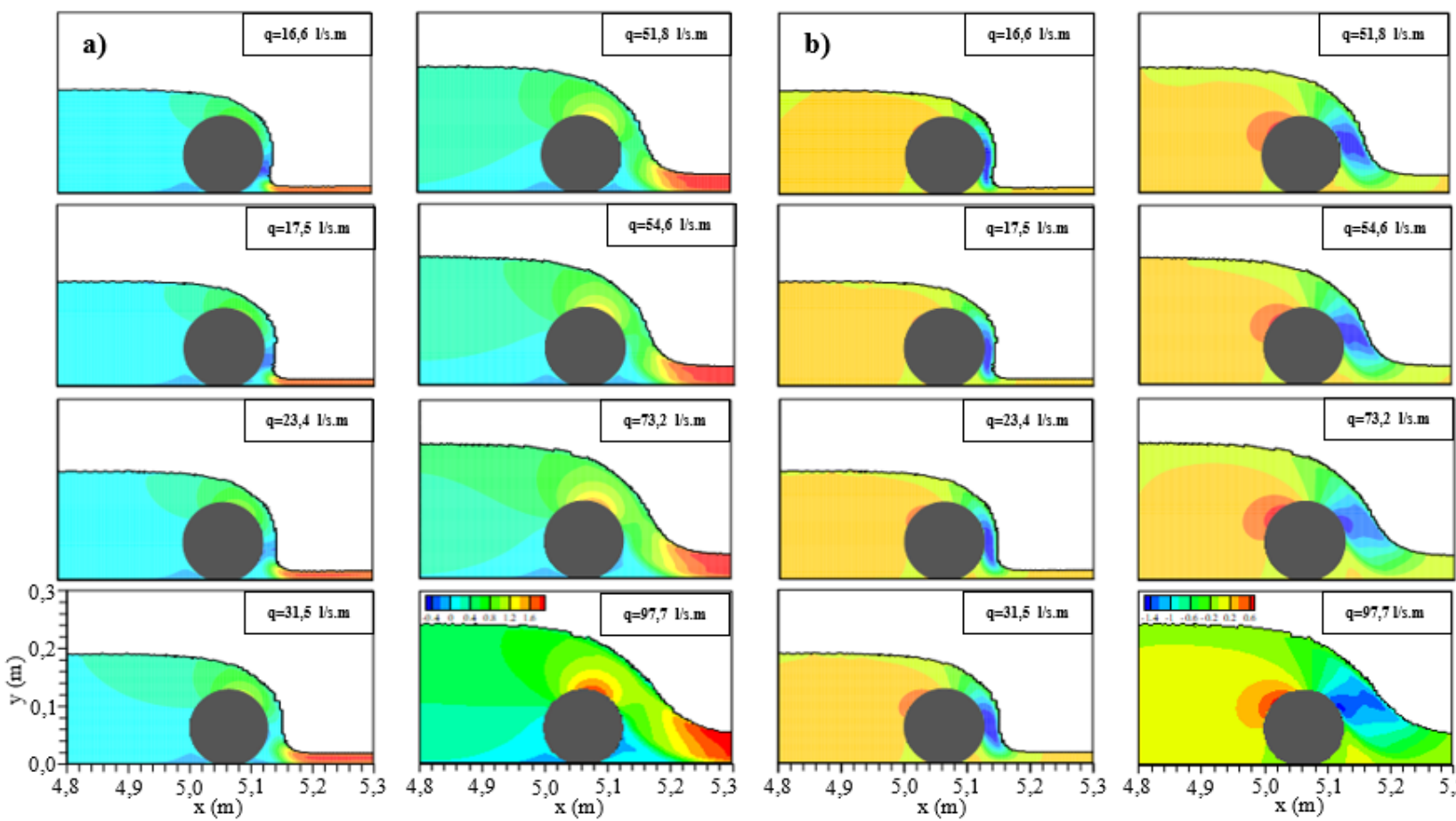

Şekil 7. Sayısal hız dağılımları a) x doğrultusundaki yatay hız, u b) y doğrultusundaki düşey hız, v bileşeni

\subsection{Deneysel ve sayısal debi katsayıları}

Bu çalışmada Heidarpour ve Chamani (2006)'nın dairesel başlıklı savaklar ile ilgili deneysel çalışmaları RNG türbülans modeli ile sayısal olarak modellenmiştir. Bununla birlikte farklı debi koşulları için de sayısal modelleme yapılmış, bu modellemelerden elde edilen sayısal $C_{\mathrm{d}}$ değerleri literatürde bulunun deneysel debi katsayıları ile karşılaştırılması Şekil 8'de verilmiştir. Yapılan karşılaştırma neticesinde RNG türbülans modeli kullanılarak elde edilen debi katsayılarının deneysel verilerle oldukça uyumlu olduğu sonucuna varılmıştır. Dolayısıyla yapılan deneysel çalışmalara ilaveten hesaplamalı akışkanlar dinamiği yöntemi kullanılarak farklı akım ve yapı koşulları için debi katsayılarının güvenilir bir şekilde elde edilebileceği sonucuna varılmıştır. Şekil incelendiğinde RNG türbülans modeli ile elde edilen $C_{\mathrm{d}}$ debi katsayısı değerlerinin deneylere göre az da olsa fazla olduğu görülmüştür. Ancak RNG türbülans modeli ile toplam enerji yüksekliği kullanılarak Denklem (1) ile elde edilen sayısal $C_{\mathrm{d}}$ değerlerinin deneysel verilere oldukça yakın olduğu söylenilebilir. Bununla birlikte $C_{\mathrm{d}}$ değerinin $H / R$ oranının artmasıyla artış gösterdiği görülmektedir.

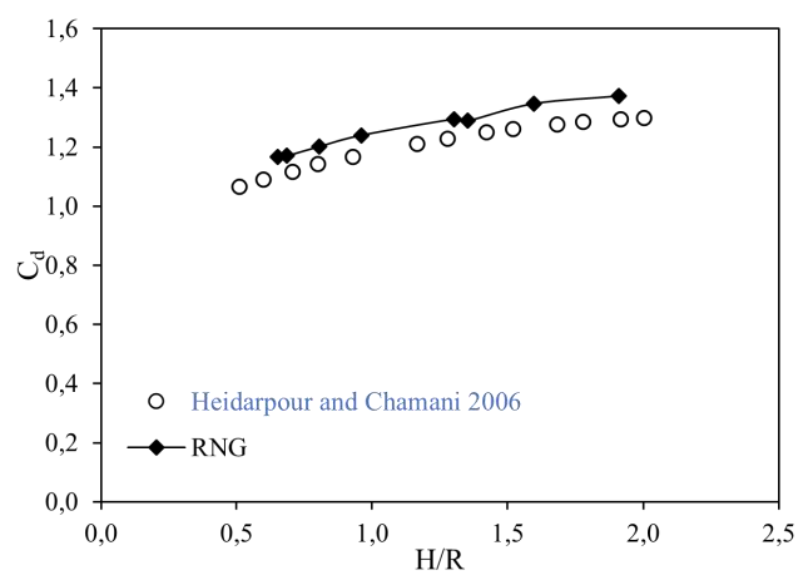

Şekil 8. $C_{\mathrm{d}}$ debi katsayısının spesifik toplam enerji yüksekliği $(H / R)$ bağlı değişimi

\subsection{Akım çizgileri ve hız vektörleri}

Şekil 9 ve $10^{\prime} \mathrm{da}$, silindir savak üzerinden geçen akımın RNG türbülans modeli ile 8 farklı debi durumu için sayısal hesaplama sonuçları neticesinde belirlenen akım çizgileri ve hız vektörleri görülmektedir. Daha düşük hızların görüldüğü memba bölgesinde akım kritik altı rejim biçimindedir. Akım yapı üzerinde kritik derinlikten geçerek mansap bölgesinde kritik üstü akım rejimine ulaşmaktadır. Akım rejimine bağlı olarak akım hızlarında bölgesel olarak meydana gelen artış ve azalmalar hız vektörlerinden açıç̧a görülmektedir. Savak etrafındaki akım çizgileri ve hız vektörleri incelendiğinde savağın hemen membasındaki ayrılma bölgesi, açıçca yer almakta, boyut ve şekil itibariyle benzer özellikler 
göstermektedirler. Savağın membasındaki ayrılma bölgesi debinin artması ile az da olsa artış göstermiştir. Bununla birlikte savağın mansabında
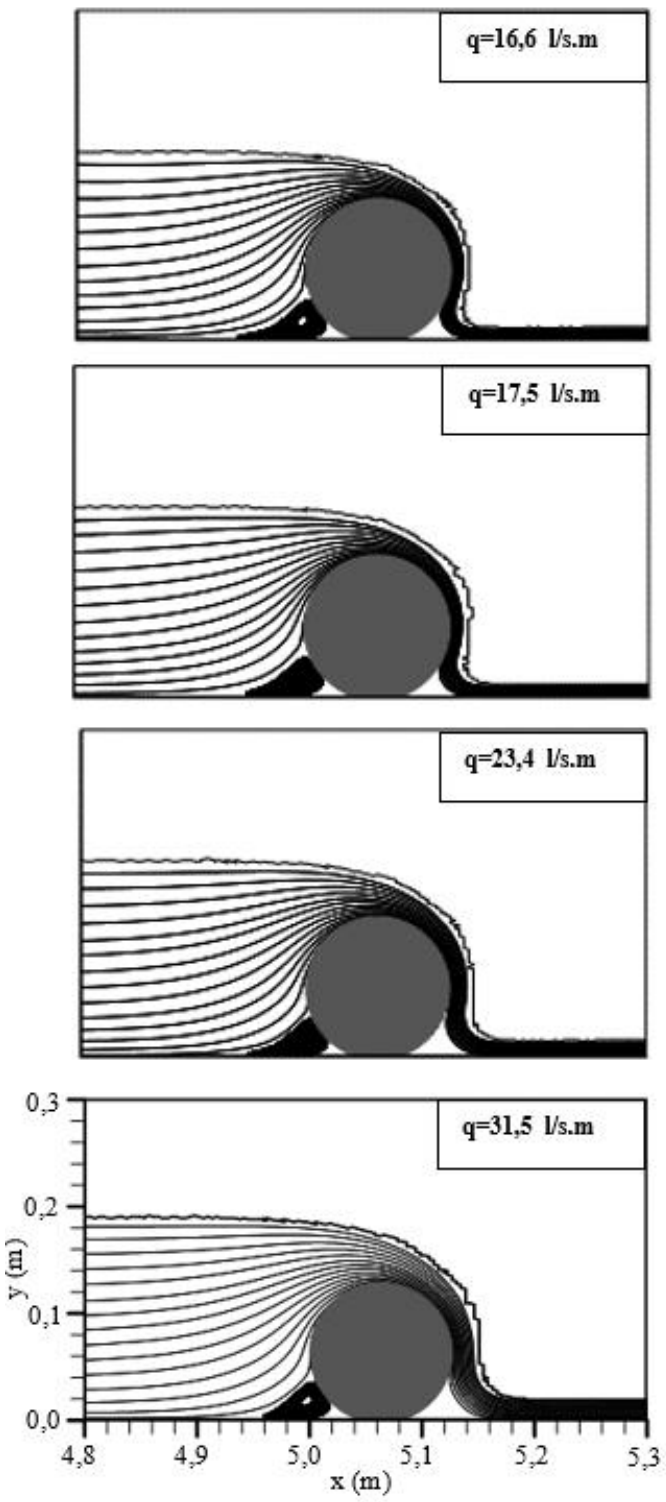

Şekil 9. Sayısal akım çizgilerinin dağılımı oluşan ayrılma bölgesi debi değerinin artmasıyla birlikte belirgin bir şekilde artış göstermiştir.
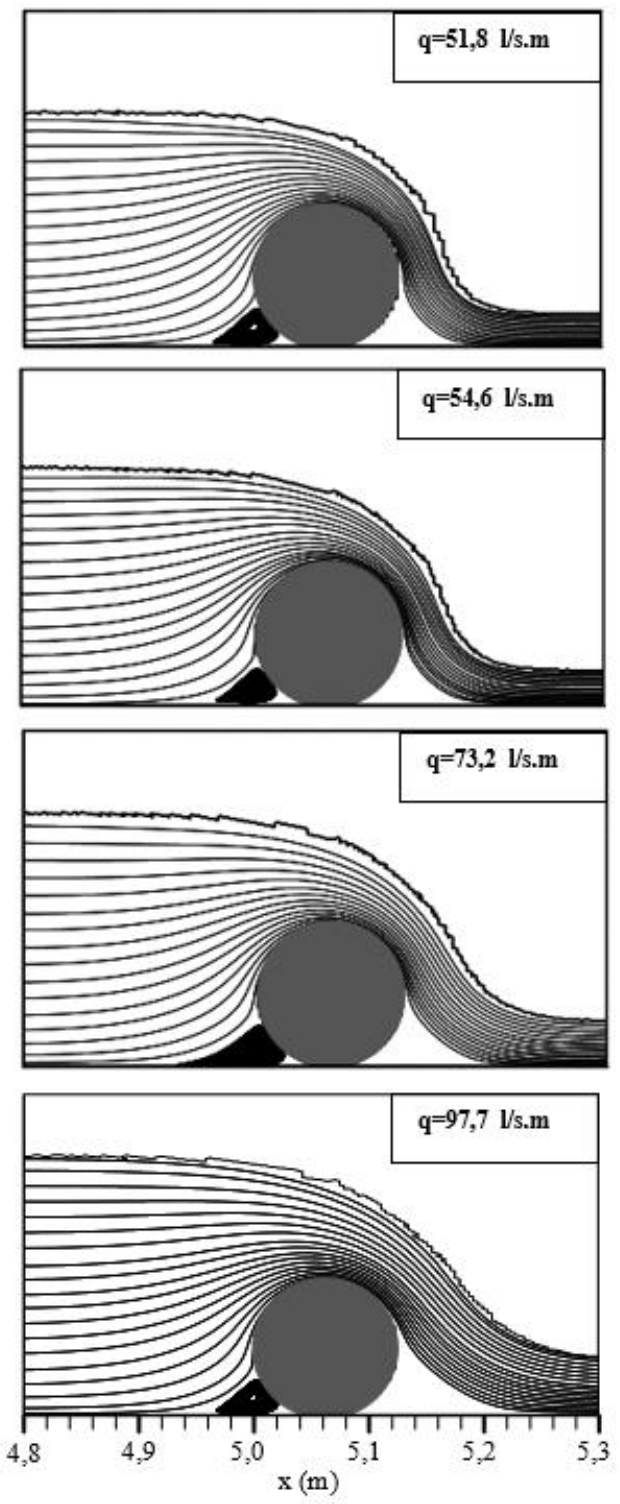

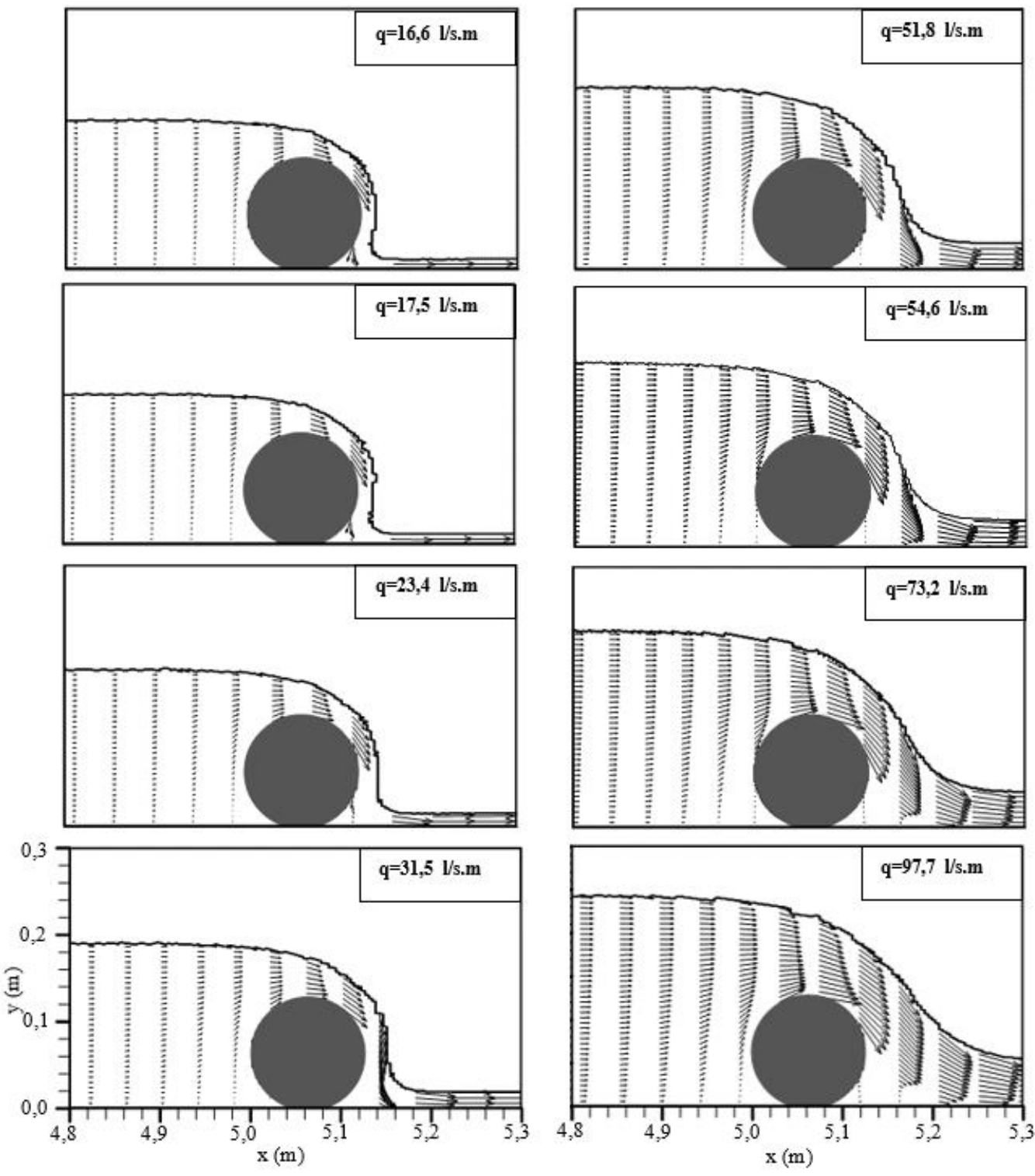

Şekil 10. Sayısal hız vektörleri

\subsection{Saylsal su yüzü profilleri}

Şekil 11'de, silindir savak üzerinden geçen 8 farklı akım koşulu için RNG $k$ - $\varepsilon$ türbülans modeli ile sayısal modellemelerden hesaplanan su yüzü profilleri verilmiştir. Debinin artmasıyla birlikte savak membasında meydana gelen kabarmanın arttığ1 görülmektedir. Bu kabarmanın etkisiyle

savağın membasındaki eğriselliğin debinin artmasıyla artış gösterdiği ancak savağın mansap bölgesinde akım eğriselliğinin azaldığı açıkça görülmektedir. Bu durum savak memba bölgesinde 2 boyutlu akım etkisinin görüldüğü bölgenin, debinin artmasıyla arttığ 1 ve Şekil 7'den de görüldüğü gibi daha çok memba bölgesine kaydığını ifade eder.

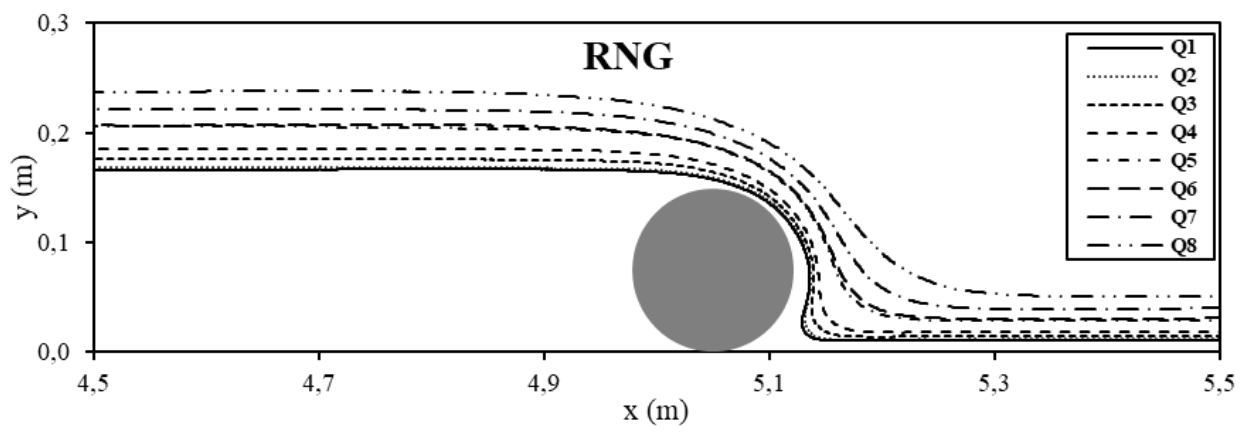

Şekil 11. Sayısal su yüzü profilleri 


\subsection{Sayısal basınç dăğllımları}

Şekil 12'de 8 farklı debi durumu için savak üzerinden geçen akımın RNG türbülans modeli ile sayısal olarak modellenmesi sonucu elde edilen sayısal basınç dağılımları görülmektedir. Basınç dağılımları incelendiğinde debinin artmasıyla birlikte kanal tabanda meydana gelen basınç değerinin arttığ görülmektedir Savak kretinin
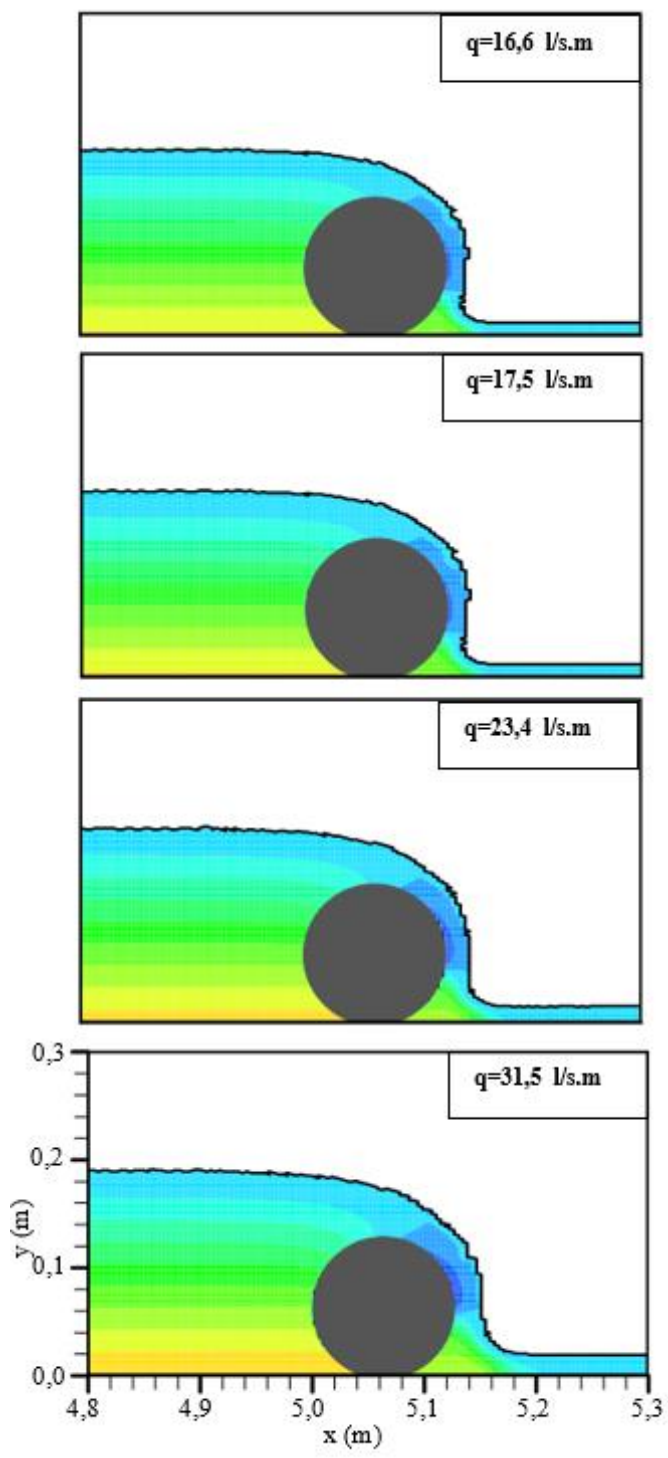

Şekil 12. Sayısal basınç dağı̆lımı

\section{Sonuçlar}

$\mathrm{Bu}$ çalışmada silindir savak etrafındaki akımın yapısı sayısal ve deneysel olarak araştırılmıştır. Literatürden elde edilen deneysel bulgular ayn1 akım koşulları için ANSYS Fluent programı yardımıyla sayısal olarak modellenmiştir. Sayısal modellemelerde akımı idare eden temel denklemler RNG türbülans modeli ile hesaplanmış olup su yüzünün sayısal olarak belirlenmesinde Akışkan Hacimleri Yöntemi (VOF) kullanılmıştır. Elde edilen sayısal hız değerleri ve debi katsayılanı mansabında ise negatif basınç gradyanını oluştuğu ve negatif basınç dağılımının görüldüğü bölgenin başlangıç ve bitiş noktasının debinin artmasıyla birlikte krete yaklaştığı görülmektedir. Bunun sebebinin akım çizgileri ve hız vektörlerinden de görüldüğü gibi savak mansabında oluşan eğri yörüngeli akım profilinin debinin artmasıyla yataylaştığı söylenebilir.
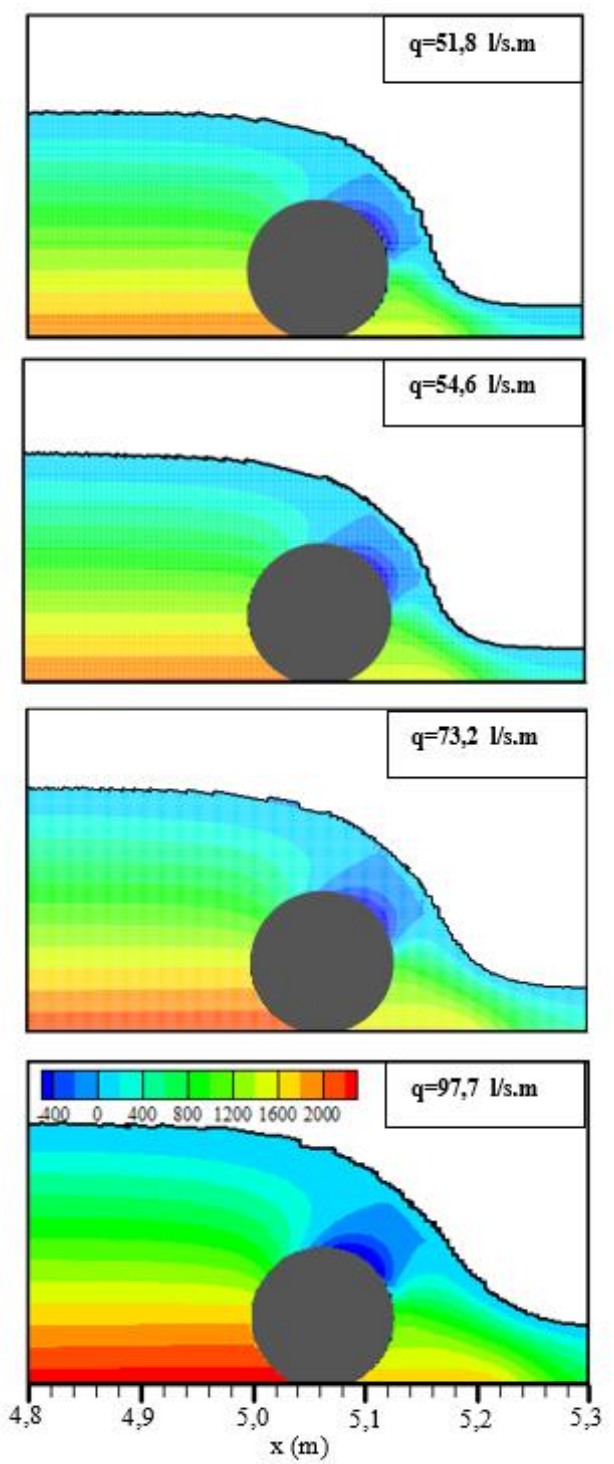

deneysel bulgularla karşılaştırılmış ve RNG $k$ - $\varepsilon$ modelinin dairesel savak etrafindaki akımı modellemede başarılı olduğu sonucuna varılmıştır. Sayısal bulguların deneylerle doğrulanmasından sonra farklı akım koşulları için ilave sayısal modellemeler gerçekleştirilmiş olup, 8 farklı debi durumu için sayısal hız dağılımları, akım çizgileri ve hız vektörlerinin topolojisi, savak etrafindaki basınç dağılımları verilmiştir. Akım debisinin artmasiyla beraber savak membasındaki ayrılmanın fazla değiş̧mediği ancak mansap 
bölgesinde ayrılma bölgesinin büyüklüğünün belirgin bir şekilde arttığı görülmüştür. Savak kretinin hemen mansabında negatif basınç gradyanının oluştuğu ve debinin artmasıyla bu bölgenin başlangıç noktasının krete yaklaştığı görülmüsstür. Ayrıca deneysel ve RNG modeli ile elde edilen debi katsayılarının gayet uyumlu olduğu ve debinin artmasıyla debi katsayısı $C_{\mathrm{d}}$ 'nin artış gösterdiği söylenebilir.

\section{Kaynaklar}

Aköz, M. S., Şimşek, O. and Soydan, N. G. (2019). Numerical modeling of interaction of turbulent flow with a buried circular cylinder on a plane surface. Teknik Dergi, 30(6), 9621-9645. https://doi.org/10.18400/tekderg.432310

Aköz, M. S., Gümüş, V. and Kırkgöz, M. S. (2014). Numerical simulation of flow over a semicylinder weir. Journal of Irrigation and Drainage Engineering, 140(6), 6, 04014016. https://doi.org/10.1061/(ASCE)IR.19434774.0000717

Ansys, (2012). Fluent Theory Guide. USA: ANSYS Inc.

Bagheri, S. and Kabiri-Samani, A. (2020). Overflow characteristics of streamlined weirs based on model experimentation. Flow Measurement and Instrumentation, $73(1), \quad 101720$. https://doi.org/10.1016/j.flowmeasinst.2020.101 720 .

Bos, M. G. (1976). Discharge measurement structures. Ilri, 161.

Chanson, H. and Montes, J. S. (1998). Overflow characteristics of circular weirs: Effects of inflow conditions. Journal of Irrigation and Drainage Engineering, 124(3), 152-162. https://doi.org/10.1061/(ASCE)07339437(1998)124:3(152).

Dönmez, S. ve Lekesiz, R. (2011). Silindir savaklar için savak katsayısı. Pamukkale Üniversitesi Mühendislik Bilimleri Dergisi, 8(1), 85-90.

Gümüş, V. ve Şimşek, O. (2015). Eğimli açık kanal akımının farklı türbülans modelleri ile sayısal modellemesi. Çukurova Üniversitesi Mühendislik-Mimarlık Fakültesi Dergisi, 30(2), 41-54.

Heidarpour, M. and Chamani, M. R. (2006). Velocity distribution over cylindrical weirs. Journal of Hydraulic Research, 44(5), 708-711. https://doi.org/10.1080/00221686.2006.9521719

Hirt, C. W. and Nichols, B. D. (1981). Volume of fluid (vof) method for the dynamics of free boundaries. Journal of Computational Physics, 39(1), 201-225.

Kırkgöz, M. S. and Ardıçlıoğlu, M. (1997). Velocity profiles of developing and developed open channel flow. Journal of Hydraulic Engineering, 123(12), https://doi.org/10.1061/(ASCE)07339429(1997)123:12(1099).

Menter, F. R. (1994). 2-equation eddy-viscosity turbulence models for engineering applications. AIAA Journal, 32(8), 1598-1605.

Rao, N. S. L. (1975). Theory of Weirs. In: Advances in Hydroscience, Elsevier, 309-406.

Schmocker, L., Halldórsdóttir, B. R. and Hager, W. H. (2011). Effect of weir face angles on circularcrested weir flow. Journal of Hydraulic Engineering, 137(6), 637-643. https://doi.org/10.1061/(ASCE)HY.19437900.0000346.

Soydan, N. G., Aköz, M. S., Şimşek, O. ve Gümüş, V. (2012). Trapez kesitli geniş başlıklı savak akımının $\mathrm{k}-\varepsilon$ tabanlı türbülans modelleri ile sayısal modellenmesi. Çukurova Üniversitesi Mühendislik-Mimarlık Fakültesi Dergisi, 27(2), 47-58.

Soydan, N. G. (2019). Hidrofoil Savak Akımının Deneysel ve Sayısal Analizi. Doktora Tezi, Çukurova Üniversitesi Fen Bilimleri Enstitüsü, Adana.

Şimşek, O., Aköz, M. S. and Soydan, N. G. (2016). Numerical validation of open channel flow over a curvilinear broad-crested weir. Progress in Computational Fluid Dynamics, an International Journal, 16(6), 364-378. https://doi.org/10.1504/PCFD.2016.080055.

Yakhot, V. and Orszag, S. A. (1986). Renormalizationgroup analysis of turbulence. Physical Review Letters, 57(14), 1722-1724.

Yakhot, V. and Smith, L. M. (1992). The renormalization group, the $\varepsilon$-expansion and derivation of turbulence models. Journal of Scientific Computing, 7(1), 35-61. https://doi.org/10.1007/BF01060210.

Yuce, M. I., Al-Babely, A. A. H. and Al-Dabbagh, M. A. (2015). Flow simulation over oblique cylindrical weirs. Canadian Journal of Civil Engineering, 42(6), 389-407. https://doi.org/10.1139/cjce-2014-0157.

Wilcox, D. C. (2006). Turbulence Modeling for Cfd (third edition). California: DCW Industries, Inc. 